\title{
La promotion artisanale et industrielle dans la coopération suisse au développement
}

Förderung von Gewerbe und Industrie in der schweizerischen

Entwicklungszusammenarbeit

Hilmar Stetter et Jean-Pierre Wolf

\section{OpenEdition}

Édition électronique

URL : http://journals.openedition.org/aspd/1251

DOI : 10.4000/aspd.1251

ISSN : 1663-9669

Éditeur

Institut de hautes études internationales et du développement

Édition imprimée

Date de publication : 1 janvier 1987

Pagination : 191-225

ISSN : 1660-5934

Référence électronique

Hilmar Stetter et Jean-Pierre Wolf, « La promotion artisanale et industrielle dans la coopération suisse au développement », Annuaire suisse de politique de développement [En ligne], 6 | 1987, mis en ligne le 09 mars 2013, consulté le 08 septembre 2020. URL : http://journals.openedition.org/aspd/1251 ; DOI https://doi.org/10.4000/aspd.1251

Ce document a été généré automatiquement le 8 septembre 2020

(c) The Graduate Institute | Geneva 


\section{La promotion artisanale et industrielle dans la coopération suisse au développement}

Förderung von Gewerbe und Industrie in der schweizerischen

Entwicklungszusammenarbeit

Hilmar Stetter et Jean-Pierre Wolf

\section{NOTE DE L'ÉDITEUR}

En français, résumé seulement. Lire l'article original en allemand dans Schweizerisches Jahrbuch für Entwicklungspolitik : « Förderung von Gewerbe und Industrie in der schweizerischen Entwicklungszusammenarbeit », http://sjep.revues.org/1074.

\section{RÉSUMÉS}

En politique de développement, la discussion sur les stratégies d'industrialisation compte parmi les thèmes les plus anciens et les activités dans le secteur artisanal/industriel font partie du répertoire classique de l'aide au développement. Toutefois, ce n'est que vers les années 1980 qu'un regain d'intérêt de la part des organismes de développement se manifeste et que leurs efforts porteront prioritairement sur ce secteur. Il va sans dire que la situation économique difficile de la plupart des pays en développement, la croissance de leur endettement et l'augmentation du chômage sont des raisons suffisantes pour favoriser et encourager le secteur clef qu'est la promotion artisanale et industrielle. 
L'objectif de cet article est de présenter, d'une part, les activités typiques menées par les organisations suisses à la promotion de l'artisanat et de l'industrie dans le cadre de la coopération au développement et, d'autre part, de montrer au lecteur les dimensions de l'enjeu de cette promotion.

Dans le chapitre introductif, la promotion artisanale/industrielle est placée dans son contexte historique. Suit un inventaire des différentes notions utilisées pour désigner les sous-secteurs qui font l'objet de ces interventions promotionnelles.

Le deuxième chapitre présente les activités dans le secteur artisanal/industriel de cinq agents de coopération au développement. Il s'agit de la DDA, Swisscontact, Swissaid, FUNDES et le bureau de l'ONUDI à Zurich. Cette présentation est suivie d'une comparaison montrant les différences et ressemblances des activités menées par les organismes sélectionnés.

Les questions méritant une réflexion approfondie sur les résultats escomptés de la promotion du secteur artisanal/industriel font l'objet du troisième chapitre. Il s'agit de questions relatives au type de relations entre les sous-secteurs de l'économie ; aux différentes conceptions de la gestion d'entreprise ; à la participation des bénéficiaires, aux choix des technologies et aux influences conjoncturelles sur les résultats de la promotion. 